\title{
Net-biting and escape behaviour in farmed Atlantic cod Gadus morhua: effects of feed stimulants and net traits
}

\author{
Børge Damsgård ${ }^{1, *}$, Erik Høy ${ }^{2}$, Ingebrigt Uglem ${ }^{3}$, Richard David Hedger ${ }^{3}$, \\ David Izquierdo-Gomez ${ }^{4}$, Pål Arne Bjørn ${ }^{1,5}$ \\ ${ }^{1}$ Nofima, PO Box 6122, 9291 Tromsø, Norway \\ ${ }^{2}$ SINTEF Fisheries and Aquaculture, Brattøkaia 17C, 7010 Trondheim, Norway \\ ${ }^{3}$ Norwegian Institute for Nature Research, Tungaslletta 2,7047 Trondheim, Norway \\ ${ }^{4}$ Department of Marine Science and Applied Biology, University of Alicante, 03080 Alicante, Spain \\ ${ }^{5}$ Institute of Marine Research, PO Box 6404, 9294 Tromsø, Norway
}

\begin{abstract}
Preventing farmed fish from escaping sea cages is a major challenge for developing sustainable aquaculture practices. In this study, the individual behaviour of Atlantic cod Gadus morhua to inspect and bite the net was investigated in 4 replicate multi-patch experiments, using underwater video techniques and behavioural event recording. The experimental system included a tank enclosure where cod were presented with 6 separate net panels: duplicate pairs of plain control nets and 2 different treatment panels. Four holes were made in the treatment panels, 3 of which were mended with different repair techniques including short and loose thread ends and contrasting colour repair threads. Behavioural effects of feed stimulants were studied before, during and after a feed source was placed outside the net. The cod inspected and bit the net systematically, significantly focusing on loose threads or minor damage on the net, and the fish were capable of causing severe net damage within a few days. The observed behaviours were related to hunger level and feed stimulation, and increased significantly during times when a feed source was present outside the net wall. Few bites were observed, and almost no measureable damage was recorded to plain control panels and the area around unrepaired holes during the treatment. Repairs made with white and black threads, and loose, long ends were significantly more damaged than repairs made with short thread ends and threads of similar colour as the net. The experiments demonstrated how a behavioural approach might be used in interpretation of a practical problem in aquaculture, and the results will be useful in the development of technology and escape mitigation strategies.
\end{abstract}

KEY WORDS: Gadus morhua $\cdot$ Escape $\cdot$ Behaviour $\cdot$ Biting $\cdot$ Net $\cdot$ Feed stimulant

\section{INTRODUCTION}

Prevention of escape through improvement of husbandry and technology, as well as implementation of efficient recapture programmes, will be important for the development of a sustainable Atlantic cod Gadus morhua farming industry. Our knowledge about eco- logical and genetic impacts of escaped farmed salmonids is increasing (e.g. Naylor et al. 2005), while the knowledge of cod escapes is still sparse. The potential for negative ecological consequences is significant (Bekkevold et al. 2006). For example, research has shown that escaped farmed cod are present on spawning areas for wild cod during the 
spawning season and that wild and escaped cod are likely to interbreed (Uglem et al. 2008, 2010, Meager et al. 2009). Within sea cages, farmed cod are also capable of producing viable cod larvae which subsequently mix with larvae from wild cod in the areas around cod farms (Jørstad et al. 2008). Cod farming may thus result in genetic changes in wild cod populations in the same way as suggested for Atlantic salmon Salmo salar (e.g. Hindar et al. 2006). Furthermore, escaped farmed cod may transmit pathogens to wild populations (Øines et al. 2006) and increase predation pressure on wild salmon smolt (Brooking et al. 2006) and other fish species.

Farmed cod are most likely more prone to escape from net cage farms than for instance Atlantic salmon (Moe et al. 2007, Hansen et al. 2008). Jensen et al. (2010) studied cases of reported escapes brought forward to the Norwegian Directorate of Fisheries for the years 2006 to 2009, and among the causes for the different escape events, biological and unknown causes accounted for 25 and $27 \%$ of the total number of escaped cod, respectively, whereas in salmon farming, these 2 causes account for less than $5 \%$ of the lost fish. Escape of farmed cod was not recorded systematically until 2004, but Moe et al. (2007) estimated that up to $6 \%$ of the yearly farmed stock might have escaped during 2000 to 2005. Between 2004 and 2009, a total of 1.13 million farmed cod was reported as escaped in Norway (Norwegian Directorate of Fisheries 2012). On average, this corresponds to $1.1 \%$ of the farm stock at the end of each year (Norwegian Directorate of Fisheries 2010). The proportion of reported escaped fish in cod farming has so far been higher than in salmon farming, where on average $0.2 \%$ of the farm stock at the end of each year was reported to escape from 2004 to 2009 (Norwegian Directorate of Fisheries 2010).

A cod escape event may often be a result of major technological and operational failures, but escape through small openings in the net wall has also frequently been reported (Jensen et al. 2010). Small openings in the net pen may be a result of mechanical damage, but it is also reported that farmed cod bite or nibble the netting and thus add to the wear and contribute to the creation of holes (Moe et al. 2007, Hansen et al. 2008). The high number of fish in a net pen implies that the total impact of net-biting may represent a problem (Hansen et al. 2008). Forces exerted on the net by cod (180 g and $610 \mathrm{~g}$ body weight) have been shown to exceed the force needed to break single filaments in standard nylon twine (Høy et al. 2012). Other factors that affect the likelihood for escape through small openings include genetic differences between strains and varying hunger levels. For example, an experimental study of escape behaviour has demonstrated that Norwegian coastal cod (NCC) exhibit a movement pattern within rearing tanks that might involve higher escape risk compared to northeast Arctic cod (NEAC), and that a starvation period of $9 \mathrm{~d}$ increases escape frequencies under experimental conditions (Hansen et al. 2008).

Extended understanding of the willingness and ability of farmed cod to bite in the net cage wall will be important for development of both technology and operational routines that minimize the impact of this behaviour. The aim of this study was to examine why and to what extent farmed cod bite in the net wall in relation to feed stimulants and repairs of earlier damage in the net. This was done under experimental conditions by quantifying behavioural variation in a situation where the fish were given the opportunity to inspect and bite intact nets and nets with various damage. Effects of feed stimulants were examined by temporary introduction of bags with feed outside the net walls.

\section{MATERIALS AND METHODS}

The study was conducted at the Aquaculture Research Station in Tromsø, northern Norway. All treatment of fish was in accordance with the Norwegian Welfare Act and legislation, including the 'Regulation on Experiments with Animals' (Ministry of Agriculture and Food 1996), and the experiment was approved by the Norwegian Animal Research Authority. The fish were first-generation (F1) farmed Atlantic cod from the National Cod Breeding Programme in Tromsø, originating from a random selection of NEAC and NCC populations. The fish were hatched in May 2008, moved to the research station in July 2008, and reared in tanks under natural water temperature and light regime until the onset of the experiment on 8 October 2009. During the experimental period, 340 fish (mean size approximately $0.5 \mathrm{~kg}$ ) were reared in indoor holding tanks with unfiltered seawater and natural water temperature, and the fish were fed in excess according to standard recommendations. Fish from the holding tank were randomly distributed in 4 replicate groups of 40 fish (total 160 fish, $560 \pm 171 \mathrm{~g}, 38.9 \pm 3.3 \mathrm{~cm}$, mean $\pm \mathrm{SD}$ ). Before the transfer from the holding tanks to the observation tank, the fish were starved for $1 \mathrm{~d}$. All fish were naïve to the experimental setup. The fish were not fed during the experiment. After each replicate, the fish were anaesthetised and killed by a blow 
to the head, and body weight (gram) and total length $(\mathrm{cm})$ were measured. Sex and sexual maturation status were determined by examining the gonads. The experimental fish consisted of $44 \%$ males and $56 \%$ females, and $87 \%$ immature and $13 \%$ mature fish, with $21 \%$ of the males and $7 \%$ of the females being mature. There were no differences between the size of immature males and females, while mature fish $(41.3 \pm 3.0 \mathrm{~cm}, \mathrm{n}=21)$ were slightly longer than immature fish $(38.6 \pm 3.2 \mathrm{~cm}, \mathrm{n}=139)$. There were no major differences among the 4 replicates either in size (range 37.1-40.7 cm), gender (range $43-45 \%$ males) or maturation (range $68-100 \%$ immature).

The experimental setup was built in a large indoor observation tank (depth $1.2 \mathrm{~m}$, diameter $5.0 \mathrm{~m}$ ) with unfiltered seawater and natural water temperatures. A hexagonal tank wall made of grey tarpaulin on a metal frame was constructed within the observation tank (Fig. 1). Each of the 6 walls of this structure had a $50 \times 50 \mathrm{~cm}$ opening, with a replaceable metal frame where a net panel was attached before the onset of each replicate test. The net material used in the trials was a white, square-meshed, untreated with antifouling paint, nylon netting for salmon and cod farming, measuring $20 \times 20 \mathrm{~mm}$ bar length. The control nets were plain nets with no damage, while the modified panels had 4 symmetrically distributed vertical mesh cuts (Fig. 2). The size of the cuts was made according to the cod average circumference with the aim of preventing the cod from escaping. Each cut consisted of 3 adjacent mesh twines cut with a sharp pair of scissors leaving a clean cut with readily fluffed filaments. According to a randomized pattern setup, 3 of these holes were closed using 2 different types of mending thread, and 1 hole was left open. The holes were mended with (1) white braided nylon thread (no. 20) with long loose ends, (2) a black tarred 3-strand spun nylon thread (no. 20) with long ends similar to the white thread and (3) white braided nylon thread (no. 20) with melted non-protruding ends. In total, 24 panels were used in the 4 replicates, viz. 16 panels with holes as described above and 8 plain control panels. Prior to the start of the experiments, all net panels were photographed. After the tests, the panels were photographed again and visually examined for damage. The assessment of damage included the entire panel surface, and the holes and repairs, as described by Moe et al. (2009). Damage to net thread and mending thread was categorized according to the scores 0 (no visible wear), 1 (partly fluffed ends and abrasion) or 2 (severely fluffed ends and abrasion. The knot damage was scored as 0 (no visible changes, all knots intact), 1 (1 knot undone) or 2 (2 knots undone). A total score was then calculated for each repair as the sum of relative scores according to the maximum obtainable score in each of the 3 damage categories.

To test whether the fish bit the net focally or randomly, a feed source (a net bag with $1.0 \mathrm{l}$ fish pellets) was placed ca. $10 \mathrm{~cm}$ outside the net panels for $1 \mathrm{~h}$. Hence, the 6 net panels used in each experiment

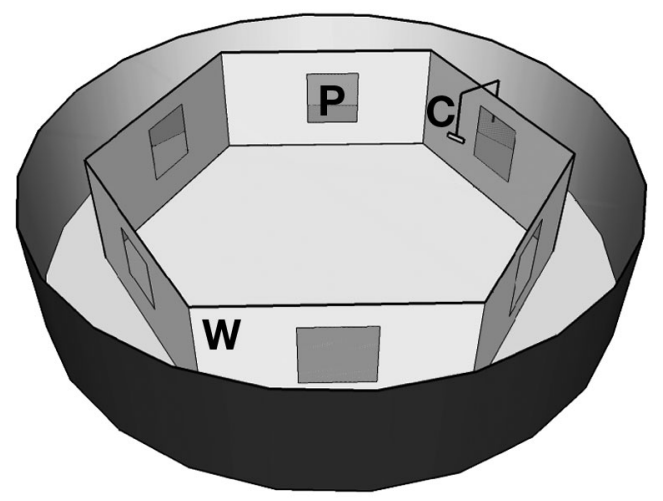

Fig. 1. Layout of the experimental system. The $5 \mathrm{~m}$ diameter observation tank had an inner hexagonal wall (W) with 6 panels $(\mathrm{P})$, video filmed by 6 underwater cameras (C)
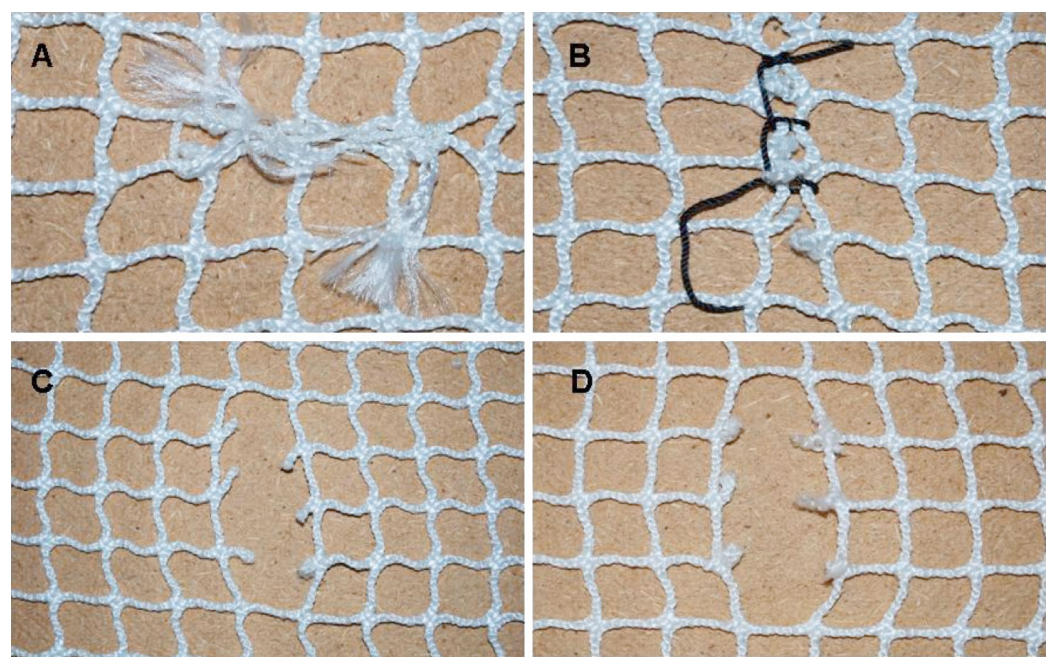

Fig. 2. Examples of the impact from cod biting behaviour on net-panel repairs; (A) knots nearly undone and the thread severely frayed, (B) 1 of 4 knots undone but with little visible damage to the black thread, (C) originally open cut with minor fraying of net twine and (D) all knots undone with the white thread completely missing and net panel twines with frayed ends 
consisted of 2 nets without any damage and feed ('Control', $\mathrm{n}=8$ in total), 2 nets with damage and with no feed ('Hole', $\mathrm{n}=8$ ) and 2 nets with damage and with feed outside ('Hole+Feed', $\mathrm{n}=8$ ). The different net types were relocated between replicates in the tank to control for possible effects of preference for specific locations within the tank.

Each replicate test lasted for $13 \mathrm{~d}$, and the 6 net panels were filmed on Days 1, 9 and 13, using underwater video cameras (Mini O, Imenco AS) at a distance of approximately $1 \mathrm{~m}$. The digital films from the 6 cameras were stored on a portable computer. Starting from 09:00 h, a total of $3 \mathrm{~h}$ from each panel were analysed, including $60 \mathrm{~min}$ prior, during and after addition of a feed source (denoted 'Pre', 'During', 'Post'), using the software program The Observer Video Pro as an event recorder (Noldus Information Technologies). The behaviour 'Inspection' was defined as a distinct and directional interest towards net structures, and the behaviour 'Biting' was defined as an evident bite, nibble or tugging behaviour. The locations of the behaviours were defined as either 1 of the 4 structures in the net, on the net itself outside these structures, or on the frames of the opening.

The inspection and bite frequency were defined as the number of inspections or bites per net divided by the number of individuals present (i.e. no. of inspections or bites net ${ }^{-1} \mathrm{~min}^{-1}$ ind. $\left.{ }^{-1}\right)$. The effect of feed stimulation (Pre, During, Post) on net inspection and biting behaviour was determined using discrete choice modelling: i.e. determining which treatment (Control, Hole, Hole+Feed) individuals chose to inspect or bite. Discrete choice modelling was done using multinomial logistic regression by application of the mlogit\{mlogit\} function in $\mathrm{R}$ ( $\mathrm{R}$ Development Core Team 2010). Given that inspection and biting behaviour may have changed as the experiment progressed, trial day $(1,9,13)$ was included as a covariate, and interaction between trial day and feed stimulation was allowed in the models. Replicate number was included as a covariate to determine whether there was a difference in inspection and biting behaviour among the replicates. The number of fish present was also included as a covariate to determine whether inspection and biting choice was affected by fish density. The effect of repair type on the total number of inspections and total number of bites was determined using Kruskal-Wallis ranksum tests.

\section{RESULTS}

\section{Effect of feed stimulation on inspection behaviour}

During the experiment, a total number of 6560 inspections were recorded. Feed stimulation had a large effect on which net the cod inspected (Fig. 3A-C). During the feed periods, the modelled odds of inspecting the Hole+Feed treatment were 1.43 times greater than that of inspecting the Control treatment (Table 1). Overall, most inspections of the Hole+Feed treatment occurred during feed stimulation $(62.5 \%)$, with relative few occurring before $(12.5 \%)$ or after $(25.0 \%)$.

When pooling all data, individuals chose to inspect the Hole treatment more than the Control treatment Pre, During and Post feed stimulation for each of the 3 trial days (Fig. 3A-C). However, this behaviour was not consistent across replicates. Whereas in replicate 3 , the modelled odds of inspecting the Hole treatment was 2.59 that of the Control treatment (Table 1),

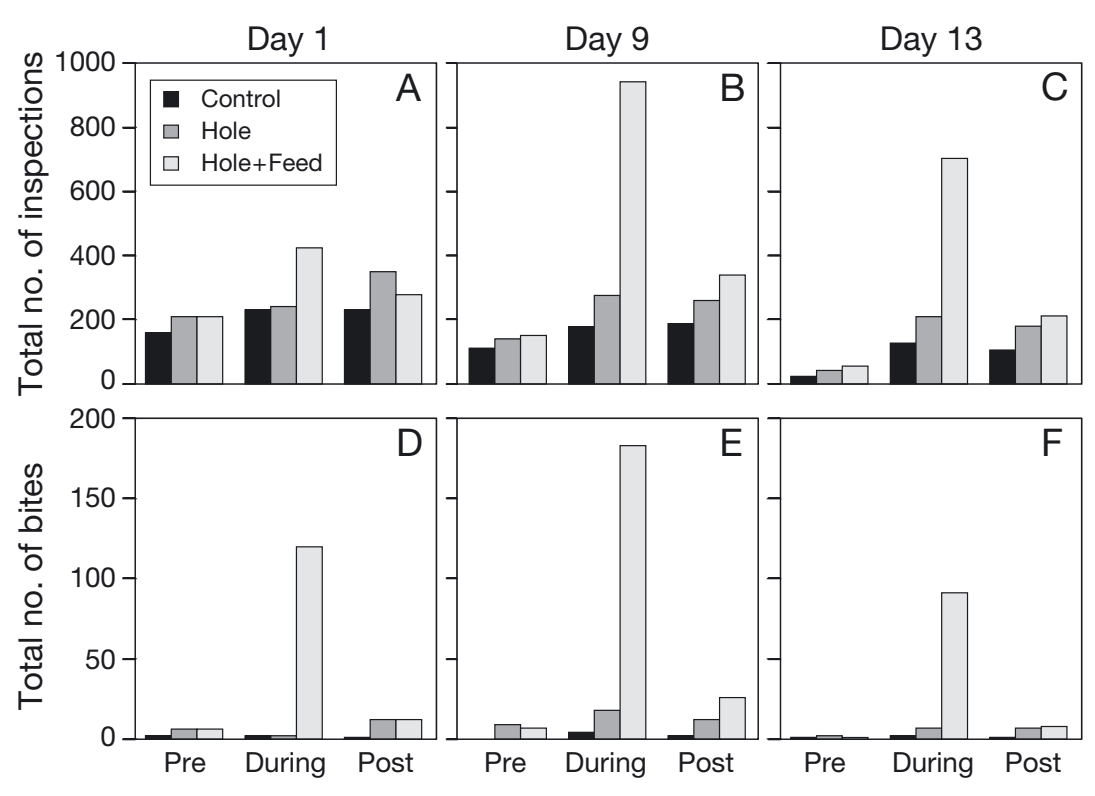

Fig. 3. Gadus morhua. Effect of treatment (Control, Hole, and Hole+Feed; see 'Materials and methods' for treatment details) on total number of inspections, pre-, during and post-feed stimulation for (A) trial Day 1, (B) Day 9 and (C) Day 13. Effect of treatment on total number of bites, pre-, during and post-feed stimulation for (D) Day 1, (E) Day 9 and (F) Day 13. This and subsequent barplots were created from the data rather than estimated by statistical models 
Table 1. Gadus morhua. Effects of feed stimulation, trial day and replicate on inspection behaviour in Atlantic cod. Non-significant results are not shown. Treatment details are provided in 'Materials and methods'. The result shows the estimate of the regression coefficient, including the standard error of the estimate (SE). The $t$-value shows the test statistic (estimate/SE), and the $\operatorname{Pr}(|t|)$ shows the probability that the null hypothesis (estimate is 0 ) is rejected. The odds ratio shows the probability of inspection relative to the control group

\begin{tabular}{|llrrrrr|}
\hline \multicolumn{2}{r}{ Treatments causing a significant effect } & Estimate & SE & $t$ & Pr(|t|) & Odds ratio \\
\hline Hole & Replicate 3 & 0.95 & 0.14 & 6.78 & $<0.001$ \\
Hole+Feed & Feed stimulation (During): Day 9 & 0.99 & 0.20 & 4.89 & $<0.001$ & 2.59 \\
Hole+Feed & Replicate 3 & 0.48 & 0.13 & 3.65 & $<0.001$ & 1.62 \\
Hole+Feed & Feed stimulation (During) & 0.36 & 0.14 & 2.65 & 0.008 & 1.43 \\
Hole+Feed & Day 13 & 0.84 & 0.35 & 2.40 & 0.016 & 2.32 \\
Hole & Replicate 4 & -0.25 & 0.11 & -2.30 & 0.021 & 0.78 \\
Hole & Feed stimulation (During): Day 9 & 0.43 & 0.22 & 1.97 & 0.049 & 1.53 \\
\hline
\end{tabular}

in replicate 4 there tended to be less inspection in the Hole treatment than the Control treatment (by a factor of 0.78 ). Consistent with the results for inspection of the Hole treatment, there was increased selection of the Hole+Feed treatment in replicate 3. Some of the cod managed to get through the holes in the net wall, and consequently the number of individuals within the enclosure decreased throughout the experiment (remaining fish for trial Days 1, 9 and 13, Expt 1: 37, 34 and 27; Expt 2: 39, 35 and 32; Expt 3: 40, 36 and 34; Expt 4: 40, 31 and 26). The number of fish present in each replicate did not significantly affect which treatment nets the cod inspected.

We observed a temporal trend of increased selection of treated nets for inspection across the trial days. Firstly, there were greater odds of inspection of the Hole treatment (by a factor of 1.53) and the Hole+Feed treatment (by a factor of 2.70) than the Control treatment during feed stimulation on Day 9, and there were greater odds of inspecting the Hole+Feed treatment (by a factor of 2.32) than the Control treatment regardless of whether feed stimulation was occurring on Day 13 (Table 1).

\section{Effect of feed stimulation on biting behaviour}

During the experiment, 544 bites were recorded. Feed stimulation also strongly increased selection of the Hole+Feed treatment nets for biting (Fig. 3D-F), with modelled odds of biting these panels being 21.4 times greater than the Control treatment during feed stimulation $(p=0.005)$. Within the discrete choice model for biting, this was the only significant variable identified. In total, $83.6 \%$ of bites occurred in the Hole+Feed treatment, $13.8 \%$ in the Hole treatment, and $2.8 \%$ in the Control treatment. In the panels with the Hole+Feed treatment, $86.8 \%$ of the bites occurred during feed stimulation, 3.1\% before and $10.1 \%$ after removal of the feedbag. Biting rates at the Hole treatment were consistently greater than at the Control treatment, but not significantly so within the discrete choice model. Biting after the feedbag was removed was higher than before feed stimulation, but again this was not identified by the model as being statistically significant. Neither replicate number nor the number of fish present in each replicate affected which nets individuals chose to bite.

\section{Temporal changes in inspecting and biting behaviour}

Overall inspection rates before feed stimulation decreased throughout the experiment, with means of 0.610 (Day 1), 0.507 (Day 9) and 0.007 (Day 13) inspections per individual per $10 \mathrm{~min}$ period of observation. Overall bite rate showed a less consistent picture, with means of 0.014 (Day 1), 0.020 (Day 9) and 0.007 (Day 13) inspections per individual per $10 \mathrm{~min}$ period of observation. The effect of application of the feedbag on overall inspection and biting behaviour during and post stimulation relative to those before feed stimulation increased as the experiment progressed (Fig. 4). On the first trial day, feed stimulation led to an approximate 2 -fold increase in mean inspection intensity and an approximate 9-fold increase in mean biting intensity during feed stimulation relative to those before the feedbag application. By Day 13, these increases had risen approximately 7 - and 24 -fold, respectively. After the feedbag was removed, inspection and biting intensities were still elevated over those before stimulation, with the magnitude of this elevation increasing as the experiment progressed (Fig. 4). 

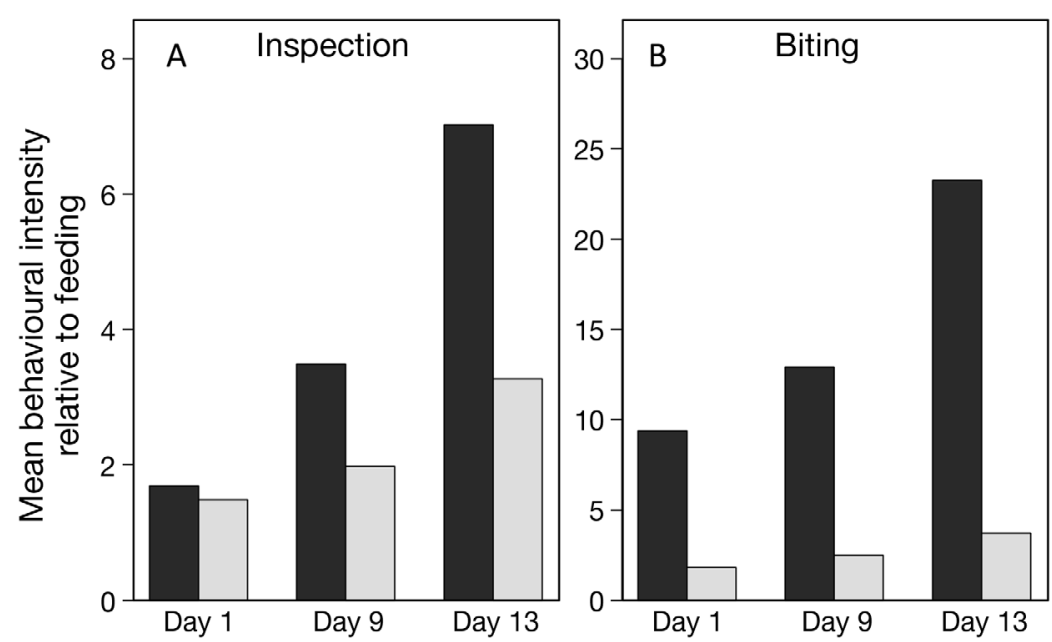

Fig. 4. Gadus morhua. Effect of feedbag insertion on biting and inspection intensity as a function of trial day; (A) mean inspection intensity relative to pre-feed stimulation, (B) mean biting intensity relative to prefeed stimulation. Dark bars indicate the intensity during feed stimulation, while grey bars are post-feed stimulation

\section{Effect of net repair type on inspection and biting behaviour}

Net repair type had a significant effect on inspection $(\mathrm{p}<0.001)$ and biting $(\mathrm{p}<0.001)$ behaviour, with both inspections and bites being most prevalent for nets repaired with black thread. The total damage score showed significant differences in how much damage was inflicted towards the 3 types of repair and the threads in the open cuts $(\mathrm{p}<0.001)$. The repairs made with white thread and loose ends showed more damage than the other repairs and the open cuts $(p<0.05)$. The repairs made with black thread and loose ends also showed significantly more damage than the open cuts and the repairs made with white thread and no loose ends. Holes mended with white thread with the ends melted into the knot and the loose threads of the open cut had little or no visible damage (Fig.5).

\section{DISCUSSION}

The present study demonstrates how escaperelated behaviours are affected both by net traits and feed stimulation, and the results are consistent with previous findings of net-biting (Moe et al. 2007, Hansen et al. 2008), confirming that Atlantic cod frequently inspect and bite the net, and try to escape through small holes in the net wall. Net failure has accounted for approximately two-thirds of the re- ported escape incidents in Norway, and biting from predators or fish, abrasions, collisions and handling procedures are among the most common reasons for holes in the net (Jensen et al. 2010). Our study demonstrates that cod focus the biting on such existing holes and net repairs, and that the hunger status of the fish may affect the escape-related behaviours.

Independent of the feed stimulation, bite rates were greater in the panels with holes compared to the control panels, and the fish generally showed little interest in the plain net wall without any holes or repairs. This result indicates that irregularities in the net wall alone may stimulate the fish to bite. Net-biting may be regarded as a part of the common behavioural repertoire of farmed cod, as suggested by Moe et al. (2007) and Hansen et al. (2008). Even though the individual biting rates were low, a corresponding biting rate in a commercial sea cage would result in a high amount of biting due to the large quantity of fish. One explanation for this net-biting might be that the cod are actively trying to create holes in the net pen wall with the purpose of escape from the cage. Indeed, the number of individuals in the experimental enclosure declined during the experiment due to

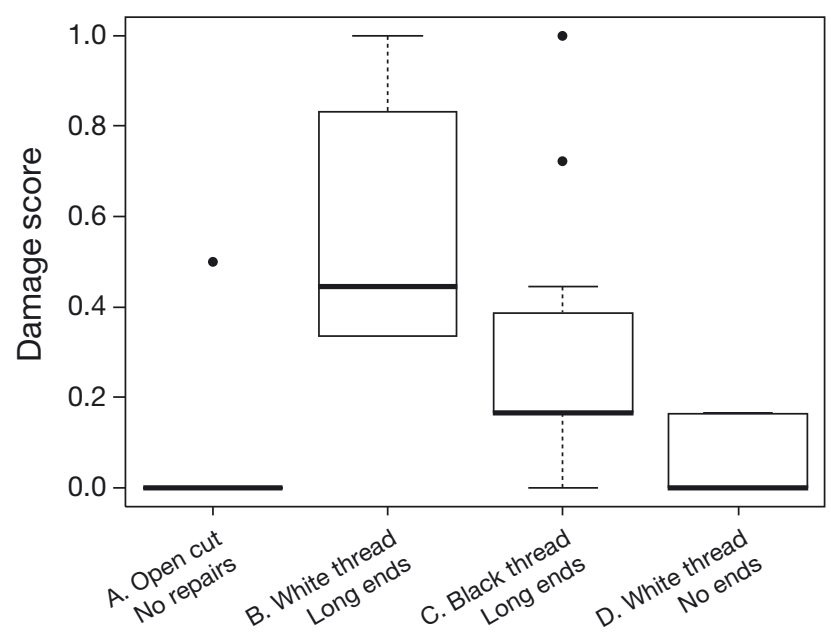

Fig. 5. Damage score box plot for net damage in open cut with no repair, white thread with long ends, black thread with long ends and white thread with no loose ends. The result is weighted relative to the maximum possible damage (knots, repair thread and net twine) where a score of 1.0 denotes a maximum combined score. The thick line in the boxplot shows the median, the box bounds the first and third quartiles, and whiskers indicate all values outside the box within $1.5 \times$ the interquartile range 
escape, even if the initial hole was smaller than the body size of the fish. It is uncertain to which degree a fish has a perception of 'inside' and 'outside', and biting behaviour does not necessarily mean that the fish is making a cognitive decision to escape. Some fish species in nature school together while other fish species are more territorial, and in some cases escapes from sea cages might be a part of a mechanism to disperse from other individuals in the population. For example, groups of Atlantic salmon normally swim in a circular pattern along the perimeter of the cage wall (Fernö et al. 1995, Juell 1995), while Atlantic cod is described as an exploratory feeder (van Duren \& Glass 1992, Hart 1993, Løkkeborg 1998), which uses a wide range of feeding strategies and thus a less regular movement pattern than salmon, increasing the chance of finding a hole in the net. For example, cod in sea cages spend much of the time close to the net wall, not coordinated with conspecifics and with a continuously changing speed and direction (Rillahan et al. 2011), corresponding with the movement pattern observed in the present study. Earlier studies of escaping cod have demonstrated that the willingness to escape is an individual trait in cod, and may also be related to the genetic background of the fish (Hansen et al. 2008). The individual relationships between willingness to escape, feeding strategies and competitive ability are likely to be complex.

The relatively clear effects of the presence of feed outside the net indicate that inspection and biting are influenced by appetite or hunger level, in addition to the effects of the net traits. One explanation is that feed may have stimulated the foraging behaviour of the fish. Inspection and biting may well be a part of the adaptive foraging behaviour of cod, as a part of a flexible learning process on how and where to feed. For example, reared and wild cod learned to enter a hole in a plexiglass wall in order to get feed, and in subsequent trials the same individuals usually went through the hole (Steingrund \& Fernö 1997). Cod of the size used in our study often stay close to the benthos where they feed on a range of taxa, including invertebrates living in the sediment or within benthic vegetation (Fahay et al. 1999), and biting of loose net twines could thus correspond to the natural foraging behaviour of cod. The increased occurrence of inspection and biting in the presence of feed could be stimulated by olfactory cues, as the chemosensory systems in fish are well developed and play an important role in the search for suitable habitats and food (Sorensen \& Caprio 1998), including in Atlantic cod (e.g. Ellingsen \& Døving 1986).
Overall inspection and biting rates before application of the feedbag declined throughout the experiment, while the relative inspection and biting rate after stimulation increased throughout the experiment. This indicates a state-dependency, suggesting that an increase in hunger levels affected how the individuals responded to feed stimulation. As fish usually live in an environment with large spatial and temporal variations, flexibility in foraging is an important adaptive trait, and fish are expected to respond to reductions in food availability with broader flexibility, including larger territories and broader diets (reviewed by e.g. Dill 1983). The willingness to inspect novel environments and potential dangerous predators is believed to be state-dependent, and, for example, hungry coho salmon Oncorhynchus kisutch were more willing to explore a risky habitat compared to fed control fish (Damsgård \& Dill 1998). This could explain why hungry cod appear to have a higher willingness to inspect novel environments, and why the biting activity increases when they perceive food outside the net. The present study confirms the state-dependency of this trait, and indicates that the fish strongly increase the biting activity in order to gain a benefit (in this case feed) on the outside of the net. The finding that differences in inspection and biting before, during and after introduction of a feedbag were more pronounced on Days 9 and 13 after initiation of the experiments compared to Day 1 also supports the assumption that hunger increases the net inspection and biting behaviour, as the hunger level would increase throughout the experiments.

In addition to the net traits and feed stimulants, several other factors may have influenced the inspection and biting frequency. Biting may, for example, be a result of conditions perceived as suboptimal or aversive, e.g. that farmed fish might be understimulated and thus have a behavioural need for something to bite. If this is so, the use of 'biting toys' or environmental enrichments may reduce biting on the nets. The finding that net irregularities and the presence of feed increase the occurrence of inspection and biting suggests that factors other than aversive conditions may explain the results of this study, but the possible effects of farm enrichments cannot be excluded. Learning can modify the behaviour of cod (e.g. Braithwaite \& Salvanes 2005, Salvanes \& Braithwaite 2005), and it is thus possible that the decline in inspection and biting in relation to time after initiation of the experiment might be a result of learning, both individual and social learning (Brown \& Laland 2003). A hungry fish is expected to be more ex- 
ploratory, but on the other hand the fish may well learn over time, and thus reduce the numbers of the inspection and biting events e.g. to optimise feeding and avoid potential dangers. In addition, some of the cod matured during the time span of the experiment, and it is known that maturation reduces feed intake in cod (e.g. Damsgård et al. 2011), eventually leading to a change in behaviour.

The net damage in the present tests was similar to what is found on used nets from commercial cod farms (Moe et al. 2009), but their trials were not accompanied by behavioural observations and did not quantify biting rates in relation to type of mending. Our results show that cod may cause substantial damage to standard nylon netting if they focus the biting on specific areas of the net. The short time span of the tests, the low fish density and the extent of net damage observed indicate that net damage due to biting could be considerable throughout a full production cycle with commercial densities of fish. However, complete netting, with no loose ends or other available features interesting to explore, showed little damage or other evidence of tugging or nibbling activity. Even though the repairs with a contrasting colour (black thread) received most focus from the cod in terms of inspection and biting, repairs made with the white thread were most damaged at the end of the trials. This may be a result of the cod devoting more attention towards visible repairs, but that the stiffer and harder black thread was more difficult to damage compared to the more loosely braided, uncoated white thread. The amount of damage indicates that if farmed cod actually possess an inherent willingness for actively escaping from the cages, they have the ability to make the requisite holes for doing so within days.

In conclusion, the study confirmed earlier findings that escape-related inspection and biting in the net were not completely random, but probably linked to the hunger level and feeding stimulation of the fish. The behavioural changes after introduction of a feed source suggest that the biting may be focused, while the differences in biting and damage suggest that some structures of the net are more vulnerable than others. The practical implications of the study are that adequate feeding regimes may reduce biting in the net, and that loose thread ends and contrasting colour repairs should be avoided.

Acknowledgements. Financial support for this study was provided by the EU project Prevent Escape, the Norwegian Research Council through the strategic research project Acoma (AS31649), and the project SECURE 184974/S40.
Thanks to the staff at the Aquaculture Research Station in Tromsø, and to T. H. Evensen for technical assistance during the experiment.

\section{LITERATURE CITED}

Bekkevold D, Hansen MM, Nielsen EE (2006) Genetic impact of gadoid culture on wild fish populations: predictions, lessons from salmonids, and possibilities for minimizing adverse effects. ICES J Mar Sci 63:198-208

Braithwaite VA, Salvanes AGV (2005) Environmental variability in the early rearing environment generates behaviourally flexible cod: implications for rehabilitating wild populations. Proc R Soc Lond B Biol Sci 272: 1107-1113

Brooking P, Doucette G, Tinker S, Whoriskey FG (2006) Sonic tracking of wild cod, Gadus morhua, in an inshore region of the Bay of Fundy: a contribution to understanding the impact of cod farming for wild cod and endangered salmon populations. ICES J Mar Sci 63:1364-1371

Brown C, Laland KN (2003) Social learning in fishes: a review. Fish Fish 4:280-288

Damsgård B, Dill LM (1998) Risk-taking behaviour in weight-compensating coho salmon, Oncorhynchus kisutch. Behav Ecol 9:26-32

> Damsgård B, Bjørklund F, Johnsen HK, Toften H (2011) Short- and long-term effects of fish density and specific water flow on welfare of Atlantic cod, Gadus morhua. Aquaculture 322-323:184-190

Dill LM (1983) Adaptive flexibility in the foraging behaviour of fishes. Can J Fish Aquat Sci 40:398-408

> Ellingsen OF, Døving KB (1986) Chemical fractionation of shrimp extracts inducing bottom food search behavior in cod (Gadus morhua L.). J Chem Ecol 12:155-168

Fahay MP, Berrien PL, Johnson DL, Morse WW (1999) Atlantic cod, Gadus morhua, life history and habitat characteristics. NOAA Tech Memo NMFS-NE-124, Northeast Fisheries Science Center, Woods Hole, MA

Fernö A, Huse L, Juell JE, Bjordal Å (1995) Vertical distribution of Atlantic salmon (Salmo salar L.) in net pens: tradeoff between surface light avoidance and feed attraction. Aquaculture 132:285-296

Hansen LA, Dale T, Damsgård B, Uglem I, Aas K, Bjørn PA (2008) Escape-related behaviour of Atlantic cod, Gadus morhua L., in a simulated farm situation. Aquacult Res 40:26-34

Hart PJB (1993) Teleost foraging: facts and theories. In: Pitcher TJ (ed) Behaviour of teleost fishes. Chapman \& Hall, London, p 253-284

Hindar K, Fleming IA, McGinnity P, Diserud O (2006) The genetic and ecological effects of salmon farming on wild salmon: modelling from experimental results. ICES J Mar Sci 63:1234-1247

> Høy E, Volent Z, Moe-Føre H, Dempster T (2012) Loads applied to aquaculture nets by the biting behaviour of Atlantic cod (Gadus morhua). Aquacult Eng 47:60-63

> Jensen Ø, Dempster T, Thorstad EB, Uglem I, Fredheim A (2010) Escapes of fishes from Norwegian sea-cage aquaculture: causes, consequences and prevention. Aquacult Environ Interact 1:71-83

Jørstad KE, van der Meeren T, Paulsen OI, Thomsen T, Thorsen A, Svåsand T (2008) 'Escapes' of eggs from farmed cod spawning in net pens: recruitment to wild stocks. Rev Fish Sci 16:285-295 
Juell JE (1995) The behaviour of Atlantic salmon in relation to efficient cage-rearing. Rev Fish Biol Fish 5:320-335

Løkkeborg S (1998) Feeding behaviour of cod, Gadus morhua: activity rhythm and chemically mediated food search. Anim Behav 56:371-378

Meager JJ, Skjæraasen JE, Fernö A, Karlsen Ø, Løkkeborg S, Michalsen K, Utskot SO (2009) Vertical dynamics and reproductive behaviour of farmed and wild Atlantic cod Gadus morhua. Mar Ecol Prog Ser 389:233-243

Ministry of Agriculture and Food (1996) Regulation on experiments with animals. Available at www.lovdata.no/ for/sf/ld/xd-19960115-0023.html

Moe H, Dempster T, Sunde LM, Winther U, Fredheim A (2007) Technological solutions and operational measures to prevent escapes of Atlantic cod (Gadus morhua) from sea cages. Aquacult Res 38:91-99

Moe H, Gaarder RH, Olsen A, Hopperstad SO (2009) Resistance of aquaculture net cage materials to biting by Atlantic cod (Gadus morhua). Aquacult Eng 40:126-134

> Naylor R, Hindar K, Fleming IA, Goldburg R and others (2005) Fugitive salmon: assessing the risk of escaped fish from net-pen aquaculture. Bioscience 55:427-437

Norwegian Directorate of Fisheries (2012) Escape statistics of farmed cod. Available at www.fiskeridir.no/statistikk/akvakultur/oppdaterte-roemmingstall

Øines Ø, Simonsen JH, Knutsen JA, Heuch PA (2006) Host preference of adult Caligus elongatus Nordmann in the laboratory and its implications for Atlantic cod

Editorial responsibility: Marianne Holmer, Odense, Denmark aquaculture. J Fish Dis 29:167-174

R Development Core Team (2010) R: a language and environment for statistical computing, $\mathrm{R}$ foundation for statistical computing, Vienna. Available at www.R-project.org

$>$ Rillahan C, Chambers MD, Howell HW, Watson WH (2011) The behaviour of cod (Gadus morhua) in an offshore aquaculture net pen. Aquaculture 310:361-368

Salvanes AGV, Braithwaite VA (2005) Exposure to variable spatial information in the early rearing environment generates asymmetries in social interactions in cod (Gadus morhua). Behav Ecol Sociobiol 59:250-257

Sorensen PW, Caprio J (1998) Chemoreception. In: Evans DH (ed) The physiology of fishes, 2nd edn. Marine Science Series. CRC Press, Boca Raton, FL, p 375-406

Steingrund P, Fernö A (1997) Feeding behaviour of reared and wild cod and the effect of learning: two strategies of feeding on the two-spotted goby. J Fish Biol 51:334-348

- Uglem I, Bjørn PA, Dale T, Kerwath S and others (2008) Movements and spatiotemporal distribution of escaped famed and local wild Atlantic cod (Gadus morhua L.) in a Norwegian fjord. Aquacult Res 39:158-170

> Uglem I, Bjørn PA, Mitamura H, Nilsen R (2010) Spatiotemporal distribution of coastal and oceanic Atlantic cod Gadus morhua sub-groups after escape from a farm. Aquacult Environ Interact 1:11-19

van Duren LA, Glass CW (1992) Choosing where to feed: the influence of competition on feeding behaviour in cod, Gadus morhua L. J Fish Biol 41:463-471

Submitted: February 17, 2012; Accepted: August 20, 2012 Proofs received from author(s): September 7, 2012 